\title{
Performance Issues and Behavioral Analysis of Routing Protocols in MANETs
}

\author{
Atinder Preet Singh, Avneet Singh Chawla, Surjeet \\ Electronics and Communication Engineering Department, Bharati Vidyapeeth College of Engineering, New Delhi, India \\ Email: atinder4@gmail.com, avneet.aries@gmail.com, surjeet.balhara@bharatividyapeeth.edu
}

How to cite this paper: Singh, A.P., Chawla, A.S. and Surjeet (2016) Performance Issues and Behavioral Analysis of Routing Protocols in MANETs. Int. J. Communications, Network and System Sciences, 9, 431439.

http://dx.doi.org/10.4236/ijcns.2016.911035

Received: August 15, 2016

Accepted: November 8, 2016

Published: November 11, 2016

Copyright $\odot 2016$ by authors and Scientific Research Publishing Inc. This work is licensed under the Creative Commons Attribution International License (CC BY 4.0).

http://creativecommons.org/licenses/by/4.0/

\begin{abstract}
Mobile ad hoc network (MANET) is an autonomous system of mobile nodes connected by wireless links. Infrastructure-less environment and frequently changing topology due to mobility of nodes makes routing a difficult task. There is no centralized control such as base station and can be set up according to demand wherever required. Effective routing protocol is required for finding the optimum path as per the application requirement. In this paper, analysis has been carried out about various basic routing protocols techniques, issues related to them especially in MANETs routing and performance comparison of different proposed approaches in terms of different network performance parameters.
\end{abstract}

\section{Keywords}

Hybrid Routing, MANETs, Proactive Routing, QoS, Reactive Routing, Routing, Wireless Networks

\section{Introduction}

The data communication is transmission of data between different devices [1]. The basic requirements of any communication system are source, destination and communication medium. The communication can be of two types based on medium used wireless or wired. The mobile ad hoc networks are wireless and they do not require any fixed infrastructure as shown in Figure 1. Mobile Ad hoc Networks (MANET) are selfconfiguring network of wireless devices with no access point or a centralized control [1]. Every node in the network is independent to join or leave the network at any time. Each intermediate node in the network can act as a router to forward a packet for path discovery. Due to node mobility, the topology of the network changes randomly and frequently. The most unique feature of a MANET is that it does not need any fixed 


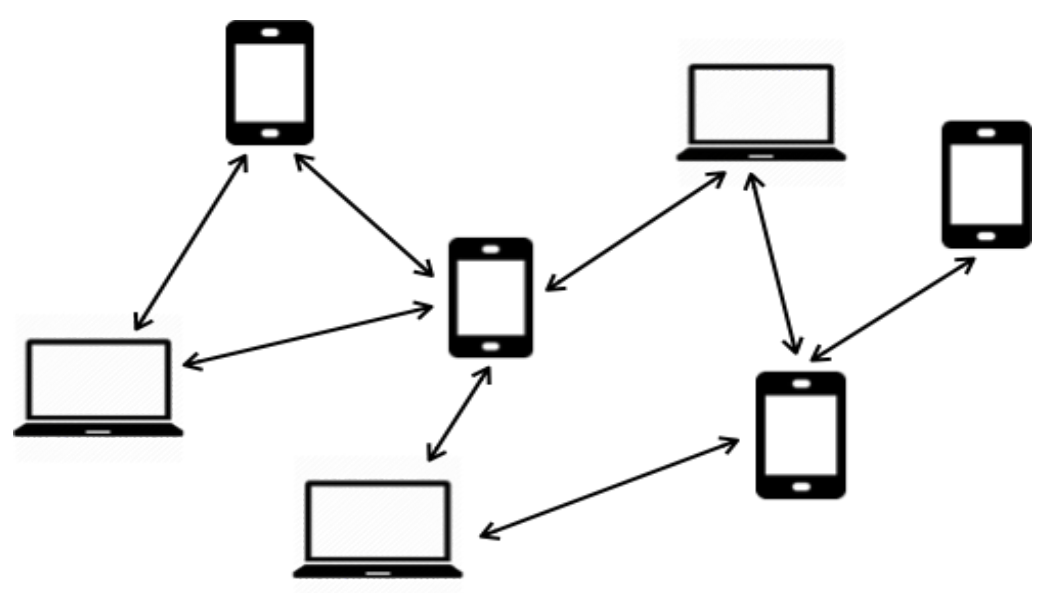

Figure 1. Mobile ad hoc network.

infrastructure. Network can be set up anywhere without the aid of any fixed infrastructure. MANETs have gained a lot of attention because of its significant advantages brought like multi-hop, infrastructure-less transmission. Due to tremendous growth in wireless technology, a lot of researches have been carried out to replace traditional infrastructure environment into the ad hoc environment. Although MANETs have changed the wireless scenario for data communication, a number of issues still remain to be touched. The most important and challenging issue is routing of data packets. As the nodes can enter or leave the network at any moment, topology changes frequently and it becomes very difficult to select a forwarding node to route the packets. To find an optimal path from the source node to the destination node also remains a challenge. The absence of a centralized control also adds to this issue.

MANETs find its application in locations with extreme terrain. The major application of mobile ad hoc networks includes sharing tactical information by military persons in Battlefield, communication in disaster such as earthquake, business associates sharing information during a meeting. MANET does not use a static network infrastructure [2] [3].

In this paper, routing related problems that arise due to unpredictable behavior of MANETs have been discussed. As there is no centralized administration or control, it becomes a challenging task to discover a desired route in such a dynamic environment. We have focused upon the most important challenge i.e. routing in such highly dynamic networks and list out various network parameters that has to be considered for data communication while designing and selecting a particular routing protocol. Analysis on performance metrics and issues related to ad hoc networks is given in Section 2 and Section 3 respectively. Different types of routing techniques have been explained in Section 4. Finally, the comparison of various routing protocols considering certain network parameters is mentioned in tabular form in Section 5.

\section{Performance Metrics}

THROUGHPUT: It is amount of data that reaches receiver successfully in given time 
period. Higher the value of throughput better is the network connection [4]. The commonly used units of throughput measurement are bits per second (bps), megabits per seconds (mbps) and gigabits per second (gbps).

END-TO-END DELAY: It is the sum of time taken from the source to the destination for a packet to reach [5]. It depends upon number of hops and congestion on the network.

JITTER: It is variation in the delay of the receiving packet [6]. The adverse effects of Jitter are observed in real time applications such as video streaming. It is caused due to congestion or improper queuing in the network.

PACKET DELIVERY RATIO: It is the ratio of number of packets received by destination to the number of packets transmitted by the source [7]. Higher the value of this ratio more reliable is the network.

\section{Issues in Ad Hoc Wireless Network}

BANDWIDTH EFFICIENCY: It is defined as ratio of bandwidth used for by data transmission to total bandwidth available [8]. In case of ad hoc networks, the bandwidth is shared among different transmission going on simultaneously in the network, so the task of protocol is to use the scarce bandwidth available effectively.

LACK OF CENTRAL COORDINATION: In case of ad hoc networks no node acts as central or master node each and every node is independent in the network [9]. This makes the diagnosis and maintenance of network difficult task.

MOBILITY OF NODES: The nodes are not stationary in ad hoc network they are mobile as they change their position [1]. Due to this dynamic nature, route discovery and establishment becomes difficult.

\section{Routing Techniques}

Routing is a process of selecting a path through which data is to be transmitted [10]. In ad-hoc network this is achieved by multi-hop wireless links. There is no fixed path defined. Each node in the network acts as a router and forwards the data packets to other nodes. To find a feasible route is one of the most important issues in the MANET. Due to highly dynamic and error prone wireless links, design and selection of the suitable routing protocol for such networks is very challenging. Because of such characteristics, any routing protocol will operate on imprecise information. As the nodes can join and leave the network, the established routing path failure can be there at any time even during the process of data transfer. Thus, the need arises of routing protocols for reliable data delivery from the source to the destination. The challenge is to find the most stable, fast and low jitter path between nodes. There are three basic types of routing protocols as shown in Figure 2.

\subsection{Proactive Protocol}

In this type of technique each node maintains a routing table that contains the information of routes to other nodes in the network [10]. However, these protocols are not 


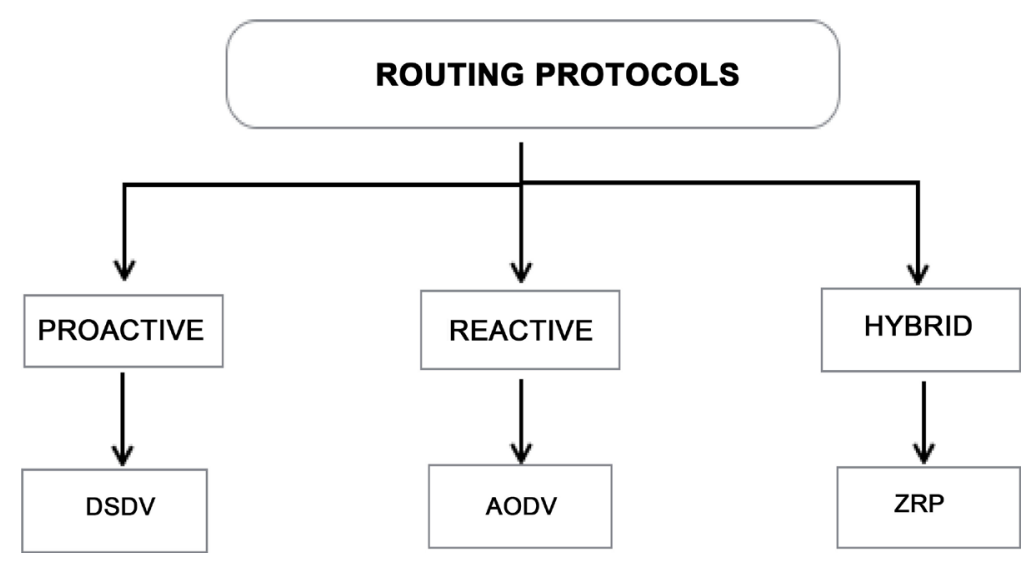

Figure 2. Types of routing protocols.

suitable for larger network due to congestion in the network caused by transmission of routing tables and periodic updates frequently. The routing information is maintained in a routing table. This table updates periodically when the network topology changes. The most commonly used proactive protocol is DSDV (Destination Sequenced Distance Vector) [11]. It is based on Bellman and Ford algorithm [12]. Each route is identified with a sequence number, which indicates how old the route is. In DSDV packets are transmitted according to the routing table [13]. The main contribution of the algorithm was to solve the routing loop problem. Each entry in the routing table contains a sequence number, the sequence numbers are generally even if a link is present; else an odd number is used. The number is generated by the destination, and the emitter needs to send out the next update with this number. Routing information is distributed between nodes by sending full dumps infrequently and smaller incremental updates more frequently.

Figure 3 describes the working of DSDV protocol. It is defined with three terms: destination node, next node and distance between them. Destination node is the node where the data is to be transmitted. Distance is defined as the number of hops from source node to destination node. In Figure 3, routing table for node 1 is shown. For instance, if the destination node is 10 , next node will be 6 and the distance would be 2 . Since, the number of hops from source node is two.

As it can be seen that in proactive or table driven protocols, each node maintains the routing information of whole network. It can be done by transmission of complete routing dump in the network or frequent updates must be sent to neighboring nodes for any change in the network. As in MANETs, due to mobility of nodes, there are frequent topology changes and route failure which needs routing tables to be updated more frequently. This makes the network congested and inefficiently utilized.

\subsection{Reactive Protocol}

These protocols are also called on-demand routing protocols. They do not maintain routing information in advance at network nodes if there is no communication. A relevant route is discovered in an on-demand manner; if a node wants to send a packet to 


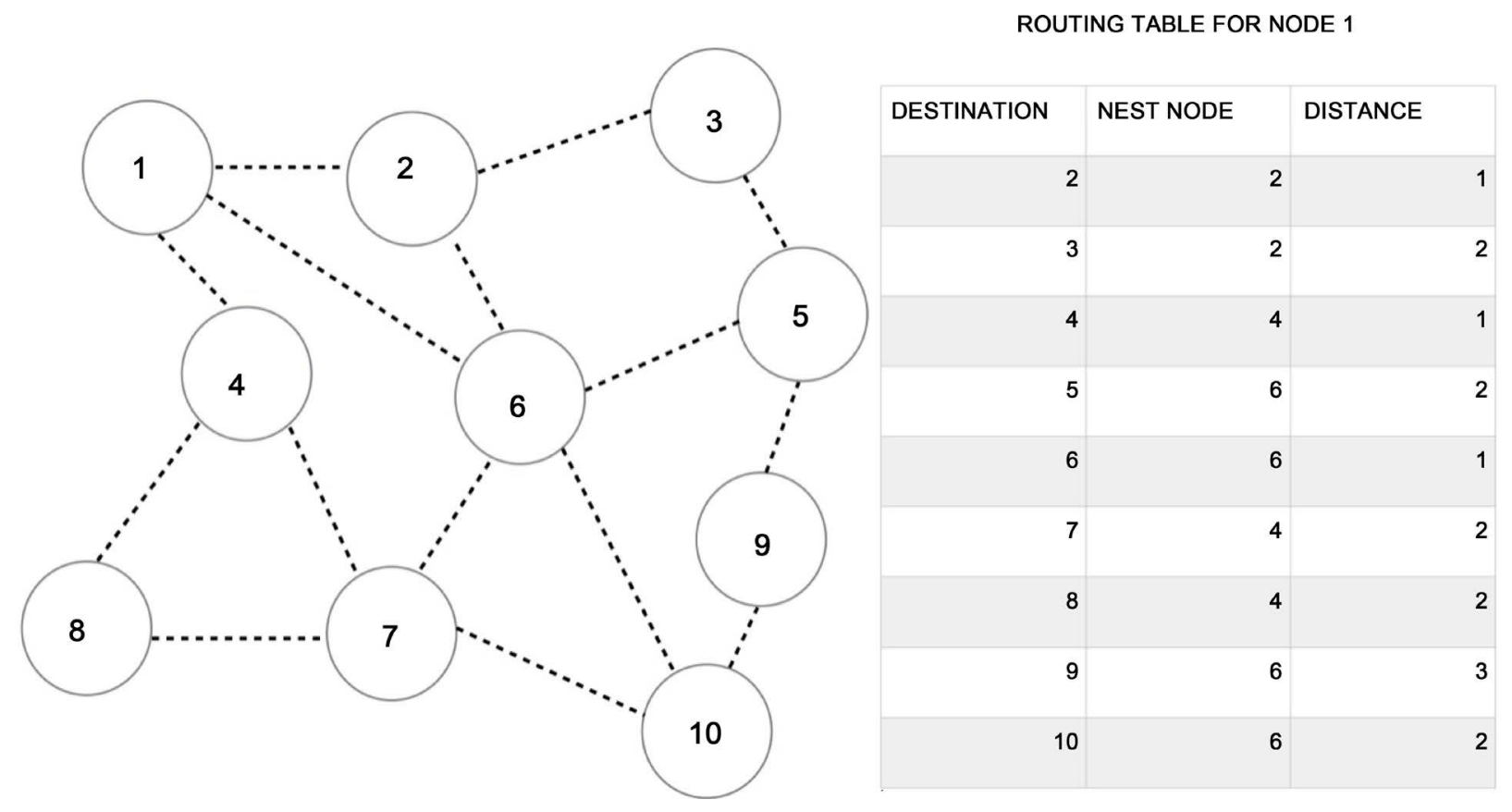

Figure 3. Mobile ad hoc network.

other node the route request packets are flooded through the entire network for the same [10].

AODV (Ad-hoc On demand Distance Vector) [14] is one of the most popular reactive routing protocols. It enables self-initiating or self-starting dynamic, multi-hop routing between mobile nodes that helps to establish and maintain ad hoc network. It searches for destination routes quickly and routes by the non-active nodes in a network that are not required to be maintained. The operation of AODV protocol is carried out with two message signals RREQ (Route Request) and RREP (Route Reply). An RREQ message is broadcasted from route discovery to a destination. The RREQ message is also used by intermediate nodes to update their routing table. When an RREQ reaches the destination node, the route is made available by unicasting RREP back to the source node. As RREP propagates towards source node, it again updates its routing table. An example of AODV protocol is shown in Figure 4, here data packets propagate from source node to destination node. The RREQ message is depicted by solid line and dotted line shows paths of RREP through symmetric link.

As we have seen that proactive protocols discovers routes with minimum hop count only despite considering the link quality and network parameters like bandwidth availability, end-to-end delay, jitter etc. As in wireless scenario, channel bandwidth is shared among multiple ongoing transmissions, so much more modifications are required to make reactive protocols suitable for MANETs.

\subsection{Hybrid Protocol}

Hybrid Routing is also commonly known as balanced-hybrid routing [10]. It is a combination of distance-vector routing, which works by sharing data to the entire network 

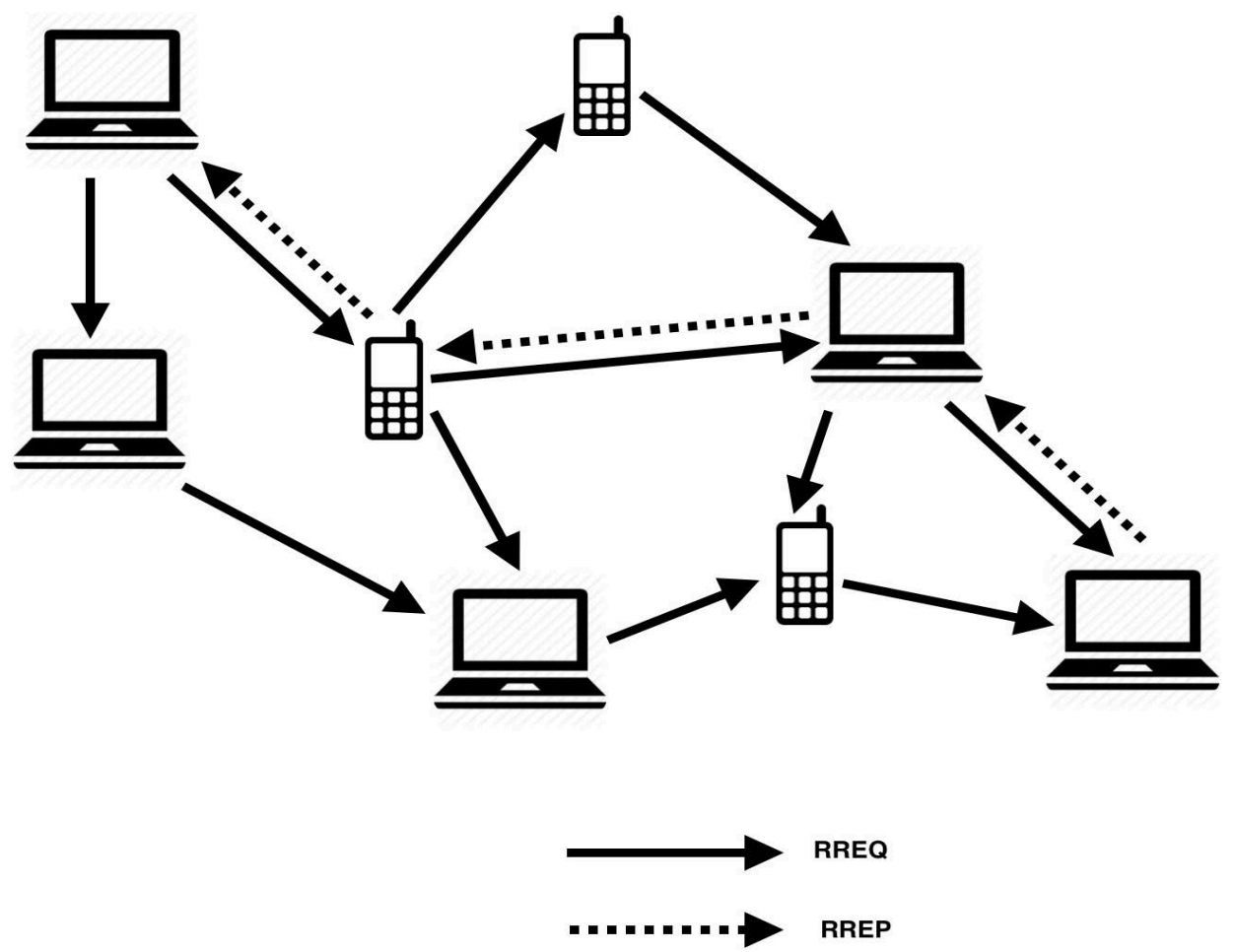

Figure 4. Working of AODV.

with its neighbors and link-state routing which works by having the routers tell every router on the network about its closest neighbors [15]. Hybrid routing protocols use distance-vectors for more accurate measurements to determine the optimum paths to destination networks, and reports the routing information only when there is any change in the topology of the network. Hybrid routing allows for rapid convergence but requires less processing power and memory as compared to link-state routing.

The ZRP (Zone Routing Protocol) is commonly used hybrid protocol. It is adaptive in nature. Proactive routing uses excess bandwidth to maintain routing information, whereas reactive routing involves long route delays [16]. Therefore, ZRP aims at improving both of these disadvantages. In ZRP, most part of the traffic is directed to nearby nodes [17]. Hence, most of the routing information available is used. Also, optimal routes can be detected and the network congestion is reduced. Nodes at the boundary of routing zone are called peripheral nodes. In ZRP each node, called source node(s) has a zone. The routing process in ZRP is divided into two parts. First, the packet is sent within routing zone of source node proactively like in DSDV protocol to peripheral nodes shown in Figure 5 and Figure 6. Then in second step the packets are sent from peripheral nodes towards destination nodes [18].

In hybrid routing protocols, they take benefit of both proactive and reactive protocols as per the applications requirement but still not considering any QoS parameters like bandwidth availability, delay, jitter or packet delivery ratio etc. for path discovery. Therefore, some network parameter constraints must be imposed on such protocols during path discovery for data transmission. 


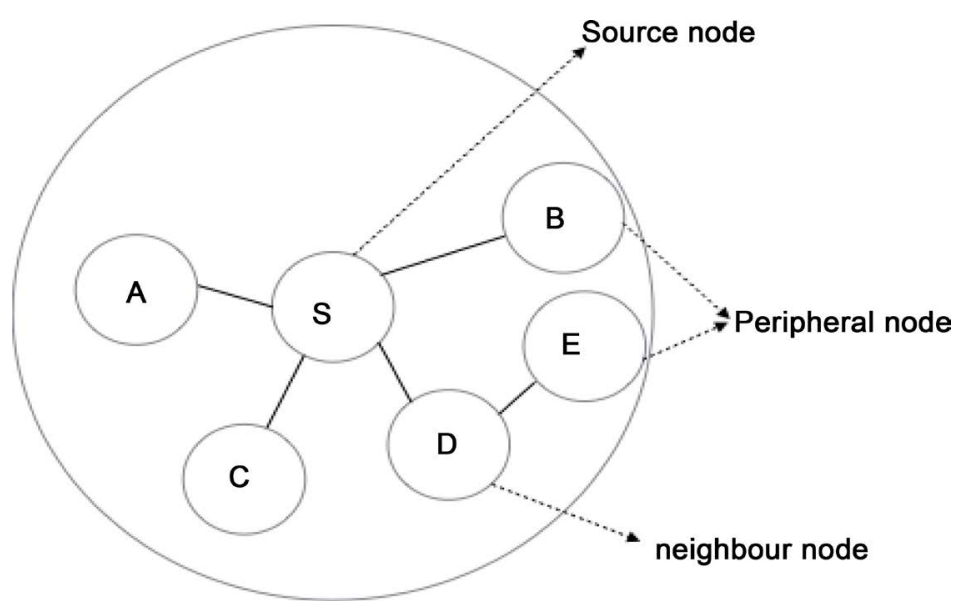

Figure 5. Routing zone for source node.

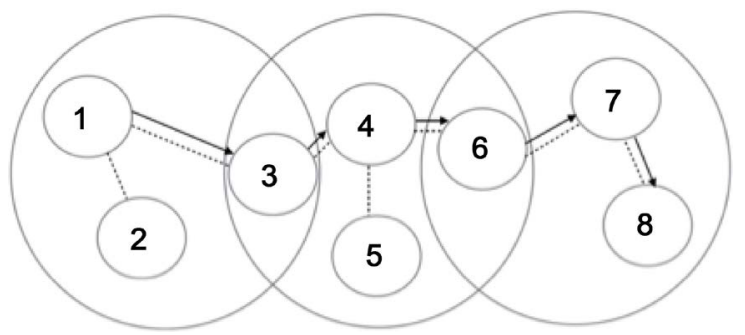

Figure 6. Zone routing protocol.

Table 1. Parameters wise comparison of different routing protocols.

\begin{tabular}{cccc}
\hline Parameter & Proactive & Reactive & Hybrid \\
\hline Route discovery & Periodically & On-demand & Both \\
Overhead cost & High & Low & Moderate \\
Reaction on failure & Slow & Fast & Fast \\
Data requirement for maintenance & Large & Small & Medium \\
Connection establishment delay & Low & High & Low \\
Probability of congestion & Low & High & Low \\
Route reconfiguration & Difficult & Easy & Easy \\
Periodic updates & Yes & No & Yes \\
\hline
\end{tabular}

\section{Comparison of Various Routing Protocols}

Please see Table 1 above.

\section{Conclusion}

In this paper, we have examined the main issues and challenges related to mobile ad hoc networks. Initially various characteristics that are unique to MANETs are discussed. The most important issue of routing due to mobility of nodes in MANETs was examined in detail. Finally, we have also discussed the various aspects that need to be 
considered for designing and selecting a routing protocol in such networks. In this research paper, an effort has been made to concentrate on the overview study of various basic routing protocols and also discussed about behavioral study and performance analysis with working diagrams. Also comparison between these routing techniques has been discussed with different parameters. The focus of the study is on the issues in MANETs especially routing and efforts are made to propose solution for routing in ad-hoc networks by tackling these core network parameters. The field of MANETs is rapidly growing and changing and while there are still many challenges that need to be met, it is likely that such networks will see widespread use within the next few years.

\section{References}

[1] Hinds, A., Ngulube, M., Zhu, S.Y. and Al-Aqrabi, H. (2013) A Review of Routing Protocols for Mobile Ad-Hoc NETworks (MANET). International Journal of Information and Education Technology, 3, 1-5. http://dx.doi.org/10.7763/ijiet.2013.v3.223

[2] Royer, E. and Toh, C.-K. (1999) A Review of Current Routing Protocols for Ad Hoc Mobile Wireless Networks. IEEE Personal Communications, 6, 46-55.

http://dx.doi.org/10.1109/98.760423

[3] Dhenakaran, S.S. and Parvathavarthini, A. (2013) An Overview of Routing Protocols in Mobile Ad-Hoc Network. International Journal of Advanced Research in Computer Science and Software Engineering, 3.

[4] Corson, S. and Macker, J. (1999) Mobile Ad Hoc Networking (MANET): Routing Protocol Performance Issues and Evaluation Considerations. ACM SIGMOBILE Mobile Computing and Communications Review, 3, 11-13.

[5] Sharma, K.K., Sharma, H. and Ramani, A.K. (2010) Modeling and Analysis of End-to-End Delay for Ad Hoc Pervasive Multimedia Network. Proceedings of the International Multiconference of Engineers and Computer Scientists, 1.

[6] Verma, D.C., Zhang, H. and Ferrari, D. (1991) Delay Jitter Control for Real-Time Communication in a Packet Switching Network. Proceedings of TriComm.

[7] Manickam, P., Guru Baskar, T., Girjia, M. and Manimegalai, D. (2011) Performance Comparisons of Routing Protocols in Mobile Ad Hoc Networks. International Journal of Wireless \& Mobile Networks, 3.

[8] Lalitha, V. and Gopinathan, B. (2015) An Survey on Energy and Bandwidth Efficiency in Mobile Adhoc Networks. International Journal for Scientific Research \& Development, 3.

[9] Kopekar, S. and Kumar, A. (2015) A Study of Ad-Hoc Wireless Networks: Various Issues in Architectures and Protocols. International Journal of Computer Applications, 122, 36-40. http://dx.doi.org/10.5120/21708-4824

[10] Abolhasan, M., Wysocki, T. and Dutkiewicz, E. (2004) A Review of Routing Protocols for Mobile Ad Hoc Networks. Ad Hoc Networks, 2, 1-22. http://dx.doi.org/10.1016/S1570-8705(03)00043-X

[11] Perkins, C.E. and Bhagwat, P. (1994) Highly Dynamic Destination-Sequenced Distance Vector Routing (DSDV) for Mobile Computers. Proceedings of the Conference on Communications Architectures, London, 31 August-2 September 1994, 234-244. http://dx.doi.org/10.1145/190314.190336

[12] Bellman, R. (1958) On a Routing Problem. Quarterly of Applied Mathematics, 16, 87-90.

[13] Peterson, L.L. and Davie, B.S. (1996) Computer Networks-A Systems Approach. Morgan 
Kaufmann Publishers Inc., San Francisco.

[14] Liu, S., Yang, Y. and Wang, W. (2013) Research of AODV Routing Protocol for Ad Hoc Networks1. AASRI Procedia, 5, 21-31. http://dx.doi.org/10.1016/j.aasri.2013.10.054

[15] Xu, D., Chiang, M. and Rexford, J. (2011) Link-State Routing with Hop-by-Hop Forwarding Can Achieve Optimal Traffic Engineering. IEEE/ACM Transactions on Networking, 19, 1717-1730. http://dx.doi.org/10.1109/TNET.2011.2134866

[16] Pearlman, M.R. and Samar, P. (2002) The Zone Routing Protocol (ZRP) for Ad Hoc Networks. IETF Draft. http://tools.ietf.org/id/draft-ietf-manetzone-zrp-04.txt

[17] Johansson, P., Larsson, T., Hedman, N., Mielczarek, B. and Degermark, M. (1999) Scenario-Based Performance Analysis of Routing Protocols for Mobile Ad-Hoc Networks. ACM Proceedings of the 5 th Annual International Conference on Mobile Computing and Networking, Seattle, 15-19 August 1999, 195-206.

[18] Sathish, S., Thangavel, K. and Boopathi, S. (2011) Comparative Analysis of DSR, FSR and ZRP Routing Protocols in MANET. International Conference on Information and Network Technology, 4, 238-243.

\section{Submit or recommend next manuscript to SCIRP and we will provide best service} for you:

Accepting pre-submission inquiries through Email, Facebook, LinkedIn, Twitter, etc.

A wide selection of journals (inclusive of 9 subjects, more than 200 journals)

Providing 24-hour high-quality service

User-friendly online submission system

Fair and swift peer-review system

Efficient typesetting and proofreading procedure

Display of the result of downloads and visits, as well as the number of cited articles

Maximum dissemination of your research work

Submit your manuscript at: http://papersubmission.scirp.org/

Orcontactijcns@scirp.org 